\title{
A prospective interventional study to compare the efficacy of syringe suction drainage system for prevention of subcutaneous seroma formation as compared to abdominal closure without a drain
}

\author{
Sharmeen Vazifdar*, Urmila G. Gavali
}

Department of Obstetrics and Gynaecology, Dr. Vithalrao Vikhe Patil Foundation's Medical College and Hospital, Ahmednagar, Maharashtra, India

Received: 17 May 2021

Revised: 09 June 2021

Accepted: 11 June 2021

\section{*Correspondence:}

Dr. Sharmeen Vazifdar,

E-mail: sharmeenvazifdar@yahoo.com

Copyright: (c) the author(s), publisher and licensee Medip Academy. This is an open-access article distributed under the terms of the Creative Commons Attribution Non-Commercial License, which permits unrestricted non-commercial use, distribution, and reproduction in any medium, provided the original work is properly cited.

\begin{abstract}
Background: Seroma is a sterile collection of serous fluid in the subcutaneous tissue. The incidence ranges from 15$81 \%$. Prophylactic drainage of wounds is aimed to reduce the wound complications and thereby the associated morbidity. Obese patients are at higher risk. There is documented beneficial effect of subcutaneous drains in obese gravida patients undergoing caesarean delivery. The most common complications of cesarean section (CS) are superficial surgical site complications including sepsis, seroma formation and breakdown. The likelihood of seroma formation without drains is 7.5 times more. Hence this study was conducted to assess the efficacy of syringe suction drainage system in prevention of seroma formation in patients undergoing CS.

Methods: The study was conducted in the Department of Obstetrics and Gynaecology at the Dr. Vithalrao Vikhe Patil Foundation's Medical College and Hospital over a period of twelve months from December 2019 to December 2020. A comparative study was conducted on 100 patients who had undergone lower segment caesarean section and had a subcutaneous layer of more than $1.5 \mathrm{~cm}$. We used a drainage system made of a nasogastric tube no 10 attached to a 10 cc disposable syringe creating negative pressure for 50 of those patients.

Results: Out of 50 patients in whom the drain was not used 7 developed discharge from wound and 2 patients developed wound gape while only 2 patients developed discharge from wound among those who had the drain placed.

Conclusion: The syringe suction drain system is an efficient and cost effective method for prevention of subcutaneous seroma in patients undergoing CS
\end{abstract}

Keywords: Caesarean section, Seroma formation, Subcutaneous drain, Obese, Syringe suction drainage system

\section{INTRODUCTION}

Caesarean section (CS) is one of the most common operations in modern obstetrics. ${ }^{1}$ The most common complication of CS seen are superficial surgical site complications including sepsis, suture breakdown and seroma formation. ${ }^{2}$ These complications are higher in obese patients. Seroma formation can further lead to abscess formation, calcification of the seroma, poor cosmetic result with unsatisfactory appearance of the surgical scar. ${ }^{3}$ It can lead to increase in hospital stay and increased morbidity alongside unnecessary patient suffering and decreased quality of life. ${ }^{4}$ There is documented beneficial effect of surgical drain in obese gravida patients undergoing caesarean section. ${ }^{5}$ The advantage of a subcutaneous drain is drainage of blood or serous fluid which may accumulate in subcutaneous space and can cause post-op pain and provide a good medium for microbial growth and infection. ${ }^{6}$ Negative suction in 
subcutaneous space has shown to reduce the incidence of infection by evacuation of collected fluid. Negative suction improves the healing capacity of the wound by reducing the bacterial load. Therefore, one of the routine practices is to use a subcutaneous drain in obese women to drain blood or serous fluid which may accumulate in the subcutaneous space. ${ }^{7}$

Here we introduce a syringe suction drainage system made of a nasogastric tube no 10 and a $10 \mathrm{cc}$ disposable syringe as a cost effective method to drain the subcutaneous space.

\section{Aim}

Aim of the research was to study the efficacy of syringe suction drainage system for prevention of subcutaneous seroma formation as compared to abdominal closure without a drain.

\section{Objectives}

Objectives were to observe the efficacy of syringe suction drainage system for subcutaneous drainage to prevent seroma formation after caesarean section; and to study the cost effectiveness of the syringe suction drainage system.

\section{METHODS}

\section{Type}

It was a prospective interventional study.

\section{Study setting}

The study was conducted in the Department of Obstetrics and Gynaecology at the Dr. Vithalrao Vikhe Patil Foundation's Medical College and Hospital over a period of twelve months from December 2019 to December 2020.

\section{Study population}

The study population consisted of women undergoing CS.

\section{Inclusion criteria}

The study included patients delivering by CS, pregnant patients with a body mass index (BMI) $>30 \mathrm{~kg} / \mathrm{m}^{2}$ in pregnancy, and subcutaneous tissue thickness more than 2 $\mathrm{cm}$ (measured using the scalpel handle which was then measured against a standard ruler).

\section{Exclusion criteria}

Patients with vertical scars, accidental removal of the drain; patients who had intraoperative complications; subcutaneous tissue thickness less than $2 \mathrm{~cm}$; comorbidities affecting seroma formation like diabetes mellitus, anemia; and patients on immuno-suppressive drugs were excluded.

\section{Procedure}

A syringe suction drainage system was created using a nasogastric tube no. 10 attached to a $10 \mathrm{cc}$ disposable syringe for creating a negative pressure. The nasogastric tube no 10 was perforated on one end and the corrugated tube was introduced into the cavity to be drained and anchored to the skin in the standard fashion. It was connected to a $10 \mathrm{cc}$ syringe. The piston of the syringe was then withdrawn to create a vacuum within the barrel and the connected tube. A constant negative pressure was maintained in this way. The entire assembly was strapped to a convenient site using a strip of transpore.

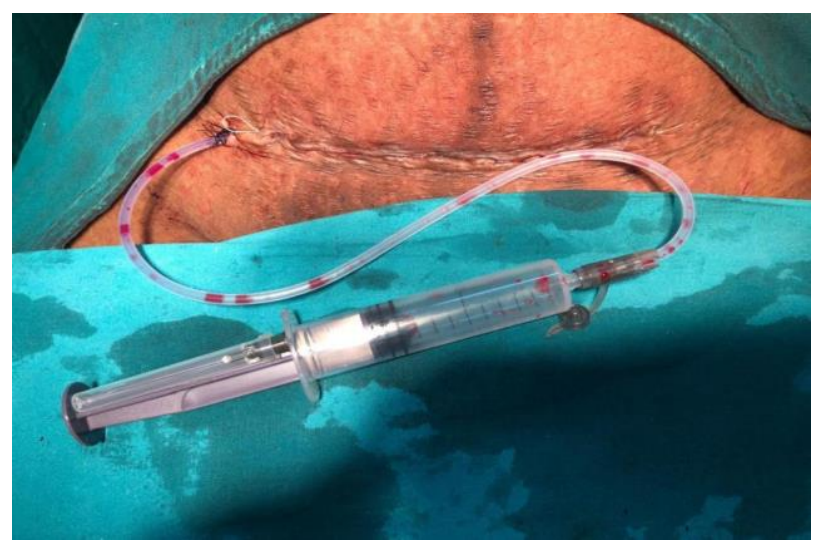

Figure 1: Image of the syringe suction drainage system in situ.

\section{Sample size}

The sample size was calculated using OpenEpi method. ${ }^{18}$

Results are rounded up to the nearest integer.

Table 1: Calculation of Odd's Ratio.

\begin{tabular}{|ll|}
\hline $\begin{array}{l}\text { X-sectional, cohort and randomized } \\
\text { clinical trial }\end{array}$ & Value \\
\hline Two-sided significance level (1-alpha) & 95 \\
\hline Power (1-beta, \% chance of detecting) & 80 \\
\hline Ratio of sample size, unexposed/exposed & 1 \\
\hline Percent of unexposed with outcome & 42 \\
\hline Percent of exposed with outcome & 14 \\
\hline Odds ratio & 0.22 \\
\hline Risk/prevalence ratio & 0.33 \\
\hline Risk/prevalence difference & -28 \\
\hline
\end{tabular}

Table: Calculation of sample size..$^{8,9}$

\begin{tabular}{|llll|}
\hline Parameter & Kelsey & Fleiss & $\begin{array}{l}\text { Fleiss with } \\
\text { CC }\end{array}$ \\
\hline Sample size exposed & 40 & 39 & 46 \\
\hline $\begin{array}{l}\text { Sample size non- } \\
\text { exposed }\end{array}$ & 40 & 39 & 46 \\
\hline Total sample size & 80 & 78 & 92 \\
\hline
\end{tabular}

$\mathrm{CC}=$ continuity correction 


\section{Data analysis}

Data was analyzed using graph pad software. Test of significance used was the Chi square test.

50 patients were taken in each group. 100 patients were included in the study. They were divided into two groups. In the first group, Group A-our syringe suction drainage system was used while in the second, group B, no drain was used. Both groups were given the same pre-operative and post-operative antibiotic prophylaxis and standard care was equally maintained in both the groups.

\section{RESULTS}

The patients in the study ranged from 20 years to 35 years. There were 15 patients between $20-25$ years in group A and 19 in the same age range in group B. From 25-30 years age, 23 patients and 20 patients were in group $A$ and group $\mathrm{B}$ respectively. And there were 12 patients between 30-35 years in group A whereas there were 11 in that age range in group B.

Table 3: Distribution of patients according to age.

\begin{tabular}{|lll|}
\hline Age in years & Group A & Group B \\
\hline $\mathbf{2 0 - 2 5}$ & 15 & 19 \\
\hline $\mathbf{2 5 - 3 0}$ & 23 & 20 \\
\hline $\mathbf{3 0 - 3 5}$ & 12 & 11 \\
\hline
\end{tabular}

Among the patients that were included in the study, 17 patients in group A were primipara and 13 patients in group B were primipara. While the number of multiparas in group A and group B were 33 and 36 patients respectively

Table 4: Distribution of patients according to parity.

\begin{tabular}{|lll|}
\hline Parity & Group A & Group B \\
\hline Primipara & 17 & 14 \\
\hline Multipara & 33 & 36 \\
\hline
\end{tabular}

Among the total 33 multipara patients in group A, 19 patients had undergone a previous caesarean section while 14 patients had had a vaginal delivery. Whereas in group $\mathrm{B}$ among the total 36 multipara patients, 24 were previous scar patients and 12 patients had delivered vaginally previously.

Table 5: Distribution of patients according to mode of previous delivery.

\begin{tabular}{|lll|}
\hline Age in years & Group A & Group B \\
\hline Previous caesarean section & 19 & 24 \\
\hline Previous vaginal delivery & 14 & 12 \\
\hline Total & 33 & 36 \\
\hline
\end{tabular}

Among the total patients selected for the study, in group A, 20 patients had a subcutaneous fat thickness between 2 -
$2.5 \mathrm{~cm} .26$ patients between $2.5-3 \mathrm{~cm}$ and 4 patients had a subcutaneous fat thickness more than $3 \mathrm{cms}$. Among the patients in group B, 25 patients had a subcutaneous fat thickness between $2-2.5,23$ patients between $2.5-3 \mathrm{~cm}$, and 2 patients had a subcutaneous fat thickness more than $3 \mathrm{~cm}$.

Table 6: Distribution of patients according to thickness of subcutaneous fat.

\begin{tabular}{|lll|}
\hline $\begin{array}{l}\text { Subcutaneous fat thickness } \\
(\mathbf{c m})\end{array}$ & Group A & Group B \\
\hline $\mathbf{3}$ & 4 & 2 \\
\hline $\mathbf{2 . 5 - 3}$ & 26 & 23 \\
\hline $\mathbf{2 - 2 . 5}$ & 20 & 25 \\
\hline
\end{tabular}

In group A, out of 50 patients in whom the drainage system was used 15 patients developed serous discharge, 7 developed infection and 2 developed wound gape. While in group $\mathrm{B}$, in whom no drain was used, 26 patients developed serous discharge, 12 developed infection and 8 developed wound gape. There was a significant difference between group A and group B with better wound healing and decreased wound seroma formation in group B.

Table 7: Distribution of patients according to presence of seroma formation.

\begin{tabular}{|lll|}
\hline Seroma formation & Group A & Group B \\
\hline Yes & 15 & 26 \\
\hline No & 35 & 24 \\
\hline
\end{tabular}

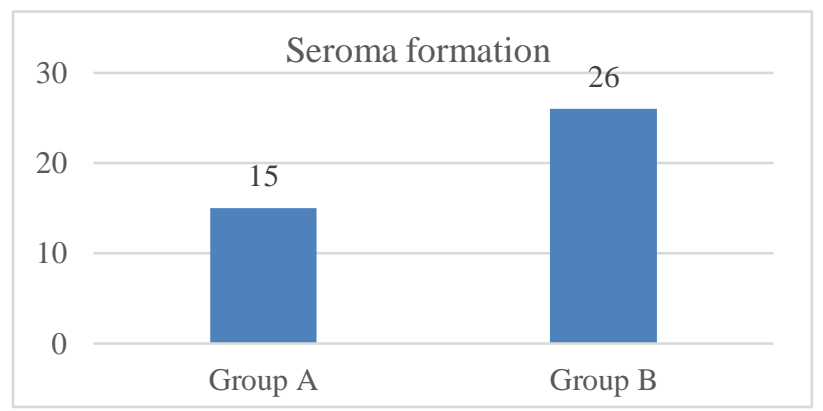

Figure 1: Distribution of patients according to presence of seroma formation.

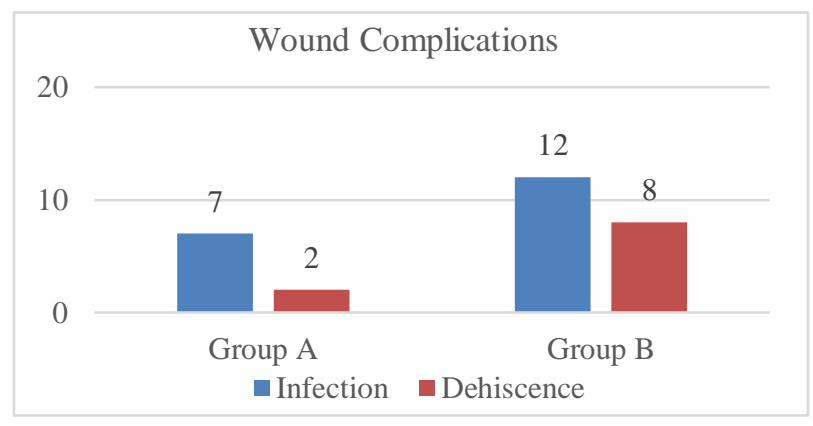

Figure 2: Distribution of patients according to wound complications. 
Table 8: Distribution of patients according to wound complications.

\begin{tabular}{|lll|}
\hline Wound complications & Group A & Group B \\
\hline Infections & 7 & 12 \\
\hline Dehiscence & 2 & 8 \\
\hline
\end{tabular}

\section{DISCUSSION}

Prophylactic drainage of wounds is aimed to reduce the wound complications and thereby morbidity. Obese patients are at more risk. ${ }^{5}$ India had the largest number of overweight and obese pregnant women (4.3 million), which accounted for $11.1 \%$ in the world. ${ }^{10}$ The objective of the present study was to determine whether subcutaneous drainage can reduce complications in obese patients undergoing caesarean section.

In a study conducted by Gates and Anderson, the patients did not show any benefit from wound drainage after caesarean section. ${ }^{11}$ In 2018 , a study conducted by Hyldig and Vinter concluded that prophylactic use of negative pressure therapy reduced the risk of surgical site infection in obese women undergoing caesarean section. ${ }^{13}$ Allaire et al compared the use of subcutaneous susture closure with subcutaneous drain in women undergoing caesarean delivery. These investigators demonstrated a reduction in the wound complication rate in women who received subcutaneous drain when compared with women treated with suture closure or those receiving neither drain or subcutaneous suture closure. ${ }^{14,15}$ In a study conducted by Gunatilake in 2017, the results of this study are consistent with other data that suggest that negative pressure therapy may reduce wound complications in high-risk women. ${ }^{16}$ In a study conducted by Bindal et al in 2017 on a group of 50 patients where drain was not used the incidence of seroma formation was found to be $26 \%$ i.e. 13 cases and out of the 50 patients in whom drain was used the incidence of seroma formation was found to be $10 \%$ i.e. 5 cases. $^{2}$ These findings were found to be comparable to our study.

The syringe suction drainage system reduces postoperative seroma formation therefore reducing the pain and morbidity in the patient. This in turn prevents prolonged hospital stay and its further financial burden on the patient. The syringe suction drainage system is cost effective as compared to others commonly used like romovac, redivac, tenrose, flexivac drainage systems. ${ }^{17}$ The cost of an arrangement is approximately Rs. 60 i.e. less than ten times the cost of the others. It is simpler to operate, easily available even at public health centres (PHCs) and therefore very suitable for a rural hospital setting.

\section{Limitations}

This study was a small scale study that was carried out with a sample size of 100 patients due to limitations in resources and difficulty in patients fitting in the inclusion and exclusion criteria. Patients who had undergone previous vertical scars (from previous caesarean section or previous laparotomy scars) were excluded from the study and therefore the efficacy of the syringe suction drainage system in preventing seroma in patients with vertical scars could not be evaluated.

\section{CONCLUSION}

The use of negative suction drainage in subcutaneous space post caesarean section in obese women reduces the incidence of postoperative seroma formation. The syringe suction drainage system is an efficient and cost effective drain for this purpose.

\section{Funding: No funding sources}

Conflict of interest: None declared

Ethical approval: The study was approved by the Institutional Ethics Committee

\section{REFERENCES}

1. Ferraro F, Piselli P, Pittalis S, Ruscitti LE, Cimaglia C, Ippolito G, Puro V. Surgical site infection after caesarean section: space for post-discharge surveillance improvements and reliable comparisons. New Microbiol. 2016;39(2):134-8.

2. Bindal J. A clinical study to compare drain versus no drain in post cesarean section. Int J Reprod Contracept Obstet Gynecol. 2017;6(9):3903-6.

3. Aksamija G, Mulabdic A, Rasic I, Aksamija L. Evaluation of risk factors of surgical wound dehiscence in adults after laparotomy. Med Arch. 2016;70(5):369.

4. Manzoor B, Heywood N, Sharma A. Review of subcutaneous wound drainage in reducing surgical site infections after laparotomy. Surg Res Pract. 2015.

5. Chowdri NA, Qadri SA, Parray FQ, Gagloo MA. Role of subcutaneous drains in obese patients undergoing elective cholecystectomy: a cohort study. Int J Surg. 2007;5(6):404-7.

6. Khalifa AA, Abdelrazak KM, Abdelazim IA. Routine subcutaneous drain versus no drain in cesarean section for diabetic obese women: a randomized controlled trial. Int J Curr Microbiol App Sci. 2015;4(8):479-85.

7. Khan AQ, Kodalkar M. Role of Negative Suction Drain in Subcutaneous Plane in Reducing Laprotomy Wound Infection. Int J Sci Re. 2016;5(1):692-4.

8. Kelsey JL, Whittemore AS, Evans AS, Thompson WD. Methods in Observational Epidemiology: 26 (Monographs in Epidemiology and Biostatistics. 2nd Edition. OUP USA. 1996.

9. Fleiss JL, Levin B, Paik MC. Statistical Methods for Rates and Proportions. 3rd Edition. Wiley Series in Probability and Statistics. 2003.

10. Chen C, Xu X, Yan Y. Estimated global overweight and obesity burden in pregnant women based on panel data model. PloS one. 2018;13(8):e0202183.

11. Gates S, Anderson ER. Wound drainage for caesarean section. Cochrane Database of Systematic Reviews. 2013;12. 
12. Maharaj D, Bagratee JS, Moodley J. Drainage at caesarean section--a randomised prospective study. South Afr J Surg. 2000;38(1):9-12.

13. Hyldig N, Vinter CA, Kruse M, Mogensen O, Bille C, Sorensen JA, et al. Prophylactic incisional negative pressure wound therapy reduces the risk of surgical site infection after caesarean section in obese women: a pragmatic randomised clinical trial. Int $\mathbf{J}$ Obstet Gynaecol. 2019;126(5):628-35.

14. Ramsey PS, White AM, Guinn DA, Lu GC, Ramin SM, Davies JK, et al. Subcutaneous tissue reapproximation, alone or in combination with drain, in obese women undergoing cesarean delivery. Obstet Gynecol. 2005;105(5):967-73.

15. Allaire AD, Fisch J, McMahon MJ. Subcutaneous drain vs. suture in obese women undergoing cesarean delivery. A prospective, randomized trial. J Reprod Med. 2000;45(4):327-31.

16. Gunatilake RP, Swamy GK, Brancazio LR, Smrtka MP, Thompson JL, Gilner JB, Gray BA, Heine RP.
Closed-incision negative-pressure therapy in obese patients undergoing cesarean delivery: a randomized controlled trial. AJP Reports. 2017;7(3):151.

17. Makama J, Ameh A. Surgical Drains. What the Resident Needs To Know. Niger J Med. 2008.

18. Karthick R. A Comparative study of Subcutaneous Single Closed Suction Drain Versus Simple Closure in Emergency Midline Laparotomy Wounds (Doctoral dissertation, Government Vellore Medical College, Vellore).

Cite this article as: Vazifdar S, Gavali UG. A prospective interventional study to compare the efficacy of syringe suction drainage system for prevention of subcutaneous seroma formation as compared to abdominal closure without a drain. Int $\mathbf{J}$ Reprod Contracept Obstet Gynecol 2021;10:2780-4. 